\title{
L'Islamisme marocain : entre révolution et intégration
}

Abdessamad Dialmy

\section{(2) OpenEdition}

1 Journals

Édition électronique

URL : http://journals.openedition.org/assr/20198

DOI : 10.4000/assr.20198

ISSN : $1777-5825$

Éditeur

Éditions de l'EHESS

Édition imprimée

Date de publication : 1 juillet 2000

Pagination : 5-27

ISBN : 2-222-96691-4

ISSN : 0335-5985

\section{Référence électronique}

Abdessamad Dialmy, "L'Islamisme marocain : entre révolution et intégration 》, Archives de sciences sociales des religions [En ligne], 110 | avril-juin 2000, mis en ligne le 19 août 2009, consulté le 19 avril 2019. URL : http://journals.openedition.org/assr/20198; DOI : 10.4000/assr.20198

Ce document a été généré automatiquement le 19 avril 2019

(C) Archives de sciences sociales des religions 


\title{
L'Islamisme marocain : entre révolution et intégration
}

\author{
Abdessamad Dialmy
}

\section{NOTE DE L'ÉDITEUR}

Ce texte a été rédigé en juin 1996. Il a été donné sous forme de conférences en octobre 1996 à l'Institut de Psychologie et de Sociologie Appliquées (IPSA) de l'Université Catholique de l'Ouest (Angers, France).

\section{Introduction}

1 Commençons par définir succintement l'islamisme. Par islamisme, nous entendons tout mouvement social basé sur l'exploitation de l'islam à des fins politiques et qui, plus précisément, tente d'exercer le pouvoir au nom de la religion seule. Les islamistes sont donc des gens obsédés par le pouvoir politique, ce sont soit des militants déçus issus de la gauche et/ou du panarabisme, soit des membres de confréries qui ne se contentent plus de l'apolitisme du soufi et de son indifférence au pouvoir. Défini ainsi, l'islamiste n'a pas en général une connaissance théologique ou juridique (fiqhique) profonde, ce qui le conduit à exiger de soi et des autres une pratique religieuse rigoureuse fondée sur le respect de la lettre des textes fondateurs. Ijtihad (effort novateur) et ta'wil (interprétation) lui sont étrangers. L'islamiste est intégriste dans le sens où il est également obsédé par des règles dont il ignore l'origine mais dont il est convaincu qu'elles sont islamiques comme le voile féminin ou la ségrégation des sexes. Dans ce sens, l'islamiste revendique la défense de l'identité arabo-islamique et de la spécificité culturelle. L'islamisme est donc une idéologie de combat dont la fonction principale est la lutte contre l'ignorance de la société et l'illégalité du pouvoir. En conséquence, il ne se pose qu'en s'opposant à des ennemis, à des autres. Le rapport qui relie le Moi islamiste aux autres, à l'Autre, est un rapport essentiellement conflictuel. Cela étant, définie comme cette inquiétante 
étrangeté par Freud, la notion de l'Autre ne convient-elle pas au caractère oppositionnel de l'islamisme (marocain)? Mais pour autant, l'islamisme en tant qu'Autre est-il condamné à demeurer Autre en raison de son caractère marginal et oppositionnel? N'assiste-t-on pas actuellement à son intégration au jeu politique ? Et n'est-il pas amené, pour s'institutionnaliser et participer à la vie politique, à accepter des concessions? Ce mouvement d'intégration englobe-t-il tous les mouvements islamistes marocains?

Pour répondre à ces questions, nous diviserons notre travail en deux parties. La première entreprendra de décrire les différents visages de l'islamisme marocain, la seconde tentera d'identifier ces autres par rapport auxquels les islamistes marocains se démarquent.

\section{I - Visages de l'islamisme marocain}

3 Traversant la société marocaine de part en part, l'islam est doté d'un capital symbolique qui revêt trois formes : 'ilm (science juridique), baraka (thaumaturgie) et sharaf (noblesse de la descendance prophétique). Accumuler $\mathrm{F}$ une de ces trois formes, c'est déjà réaliser un pouvoir, les accumuler toutes les trois, c'est réaliser un pouvoir total. Ces pouvoirs, qui ne se définissent pas comme politiques, constituent le socle de référence de tout pouvoir politique en terre d'islam. En d'autres termes, ce sont des pouvoirs politiques en puissance. Le cas de l'islamisme illustre cette thèse, car, c'est en utilisant la science juridique ('ilm) pour révolutionner la société et l'État que des mouvements sociaux, à la recherche du pouvoir politique, sont reconnus comme islamistes.

a définition de l'islamisme comme volonté de conquête du pouvoir politique permet de dresser une typologie qui conduit à distinguer, parmi les différents acteurs islamiques, ceux qu'on identifie comme islamistes. La typologie que nous proposons fait la distinction entre les confréries, les associations islamiques apostoliques, les ouléma contestataires et les associations islamistes au sens strict.

5 Concernant les confréries, en s'opposant à la modernisation - considérée comme source de corruption -, la confrérie Zituniya de Fès ne saurait être considérée comme islamiste, malgré des affrontements violents avec la police du 11 juin 1980 à Fès (trois morts). Les dix ans de prison ferme auxquels son shaykh (chef) a été condamné n'ont pas été interprétés, à juste titre, comme le résultat d'un procès politique masqué.

6 La question est plus difficile à trancher dans le cas de la confrérie Bûchichiya. Celle-ci, en recrutant dans un milieu jeune et moderne (lycéens, étudiants, ouvriers), favorable à la contestation politique, représente un danger latent, un islamisme en puissance. Si elle est tolérée par l'État, c'est en raison de ses déclarations apolitiques. En effet, elle se réclame du modèle soufi de la sainteté (la baraka comme forme privilégiée de capital), et ne peut pour cela être considérée comme un mouvement islamiste. Selon M. Tozy, cette confrérie " passa (en 1960) du statut de tariqa tabarrukiya (initiatique et source de bénédiction) à celui de tariqa tarbawiya, avec comme objectifs : l'éducation, l'encadrement... La Bûchichiya affirme n'avoir aucun projet politique sinon "d'éduquer et purifier de l'intérieur la société marocaine". Elle prétend (même) s'opposer aux islamistes qui, eux, revendiquent le pouvoir politique ${ }^{1} . .$. ». Mais en passant du tabarruk à l'encadrement de l'éducation de masse, elle devient suspecte, elle devient moralisante.

Quant à l'association At-tabligh wa ad-da'wa, fondée au Maroc en 1964, dirigée par Mohamed El Hamdaoui jusqu'à sa mort en 1987, puis par El Béchir el Younsi, c'est une association islamique apostolique plus proche du soufisme que de l'islamisme. Son objectif 
est de faire respecter les six commandements du shaykh fondateur Mohamed Ilyas (Inde). Ces six commandements sont : la bonne parole ou profession de foi, la prière, la science et la récitation mentale (dikr), le bon traitement de tout musulman, l'honnêteté, la marche sur la voie de Dieu. Sans être une confrérie-tarîq, sa finalité n'en est pas moins éducative : appel des individus à l'application de la morale islamique. At-tabligh wa ad-da'wa refuse en effet toute action politique directe. Son slogan principal est de " ne pas se mêler de ce qui ne vous concerne pas", dans trois domaines surtout: les vices de la communauté musulmane, les points de discorde entre les savants, les états des peuples. Ces considérations ont conduit $\mathrm{M}$. Darif ${ }^{2}$ à ne pas la compter parmi les associations islamistes au sens défini plus haut, à la différence de $\mathrm{A}$. Benani ${ }^{3}$ qui, tout en considérant At-tabligh wa ad-da'wa comme monarchiste et réformiste, estime que son action apostolique peut conduire à la contestation politique. Le leitmotiv selon lequel «il n'y a de puissance que celle de Dieu et de soumission qu'à Dieu seul " peut être considéré, selon ce dernier, comme une mise en garde à l'adresse du Prince quand celui-ci oublie qu'il n'est qu'un intercesseur entre Dieu et le peuple. Ici, la frontière entre da'wa simple et contestation politique est floue, la première pouvant conduire à la seconde ${ }^{4}$.

8 Si At-tabligh wa ad-da'wa incarne une convergence possible entre da'wa et contestation politique, des oulémas comme Abdelbari Ezzamzami et Abdelaziz ben Seddiq, tout en agissant à titre individuel, associent ouvertement da'wa et contestation politique. Ils symbolisent le refus de la fonctionnarisation-domestication que subit le 'alim depuis le début des années 1960, et l'intellectuel marocain ${ }^{5}$ en général depuis la fin des années 1970. Pour ces deux oulémas dits de la da'wa, l'occasion par excellence de haranguer les foules était le prêche du vendredi. C'est à ce moment-là en effet qu'ils dénoncent la dissolution des mœurs. Plus que cela, ils tiennent le pouvoir pour responsable de cette dissolution et débouchent ainsi sur la contestation politique, sur le djihad contre le pouvoir corrompu. En livrant des prêches critiques, ces oulémas, ignorent volontairement les recommandations de non ingérence politique du Ministère des Awqaf et des Affaires Islamiques ${ }^{6}$. Selon A. Ezzamzami en effet, non seulement le prêche du vendredi doit être critique, mais surtout il doit être prononcé en arabe dialectal ou en berbère et non en arabe littéraire. Par une telle attitude, la seule qui permette au prêcheur de transmettre son message aux fidèles, A. Ezzamzami signe son indépendance. Il rompt avec les recommandations du Ministère en faveur de l'arabe littéraire.

9 Ce glissement individuel de la da'wa à la contestation politique est également constatable chez A. Benseddiq au point qu'il est permis d'avancer l'hypothèse d'une synonymie entre da'wa et contestation politique, tout au moins d'une complémentarité entre les deux. A. Benseddiq défend le principe de l'indépendance du 'alim à l'égard du pouvoir, non seulement à l'occasion du prêche du vendredi, mais en toute circonstance. Quand le contenu du prêche est imposé par le ministère, Benseddiq n'hésite pas à le taxer d'illégal au regard de la Loi divine (charîa). Selon lui, c'est le pouvoir (politique) qui doit suivre et écouter le savant (religion) et non l'inverse, car c'est le savant qui connaît la Loi divine. «Les savants sont les héritiers des prophètes ${ }^{7}$ » écrit-il. Il continue en affirmant que la mission du savant, la da'wa, ne saurait être accomplie si le savant se laisse attirer par les gens du monde et corrompre par le pouvoir. Une fetwa (consultation juridique) élaborée par lui va dans ce sens; il y exprime un avis opposé à la position officielle de l'État marocain face à la guerre du Golfe. Dans la rubrique "Al-Fatawi wa al-Ahkam» (consultations juridiques et jugements) parue dans le journal Majma' al-bahrayn, Benseddiq affirme en effet que le soutien des Koweïtiens et des Séoudiens aux chrétiens 
(impies parce qu'ils ne reconnaissent pas le Coran comme parole de Dieu) est un acte illicite du point de vue de l'islam ', l'aspiration à la liberté ne pouvant à elle seule justifier un tel acte. Enfin, en engageant une polémique avec le ministre des Awqaf et des Affaires islamiques à propos du hadith « le Sultan est l'ombre de Dieu sur terre » et en démontrant que la transmission de ce hadith n'est pas sûre, Benseddiq rejette la prétention du système monarchique à la légitimité religieuse. Ce faisant, il associe ici da'wa et contestation politique d'une manière plus subversive, encore puisqu'il conteste ainsi les fondements islamiques de la monarchie. Peu après cette polémique, il est suspendu de ses fonctions de prêcheur. À cette occasion, l'association islamiste Al-'Adl wa al-Ihsan (voir plus bas) lui exprime son soutien dans un communiqué publié dans Al-htihad al-Ichtiraki ${ }^{10}$ (le quotidien du principal parti de la gauche marocaine!) et accuse ouvertement les autorités marocaines de répression et d'injustice à son égard.

Cette action individuelle d'oulémas comme Ezzamzami et Benseddiq a débouché sur la constitution d'une association éphémère des Ouléma Indépendants du Maroc, ceux de la da'wa, opposés aux oulémas du Sultan, ceux de la fetwa sur commande. L'association a publié trois communiqués. Dans le premier ${ }^{11}$, elle démontre que la décision du Ministère des Awqaf et des Affaires religieuses de suspendre les oulémas indépendants n'est fondée ni islamiquement ni juridiquement. Le deuxième communiqué ${ }^{12}$ concerne la guerre du Golfe et condamne la participation, sous la direction des Américains, d'arabes et de musulmans à cette guerre, qu'il s'agisse de l'envoi de soldats, de dons d'argent, ou tout simplement de la légitimation de cette guerre. Le troisième communiqué ${ }^{13}$, enfin, concerne le processus de paix israélo-arabe. Il déclare illicite toute cession de territoires palestiniens à l'État israélien et affirme que le djihad est la seule voie de libération de la Palestine.

11 La typologie qui distingue confréries traditionnelles, associations éducatives, islamistes en puissance, et oulémas apostoliques et islamistes à la fois ne saurait être complète sans les associations qui se définissent elles-mêmes comme islamistes au sens défini plus haut. Ces associations sont au nombre de trois: Ac-Chabiba al-Islamiya, Al-islah wa at-tajdid, Al-'Adl wa al-Ihsan. Elles se réclament de deux sources antagonistes: le salafisme wahhabite et le soufisme sunnite.

12 Contrairement au salafisme réformiste d'Allal Al Fassi, d'origine citadine et bourgeoise, qui vise à moderniser l'islam, le salafisme wahhabite de Taqi Eddine al Hilali ${ }^{14}$ vise à islamiser la modernité. D'origine bédouine, ce second salafisme est pur et dur. Il ignore «magiquement» la puissance de l'occident (le grand Autre), tandis que le premier reconnaît cette puissance et essaie de composer avec elle. Pour cette raison, le salafisme d'inspiration wahhabite est plus conforme au radicalisme des islamismes marocains.

13 Le soufisme sunnite qui se caractérise par la critique et le rejet des confréries, lesquelles sont plus ou moins considérées comme hérétiques, est la deuxième source intellectuelle de l'islamisme marocain. Abdeslam Yassine, leader de Al-'Adl wa al-Ihsan, se réclame de ce soufisme. Dans son livre Al-ihsan wa ar-rijal ${ }^{15}$ (La bienfaisance et les hommes), il fait l'éloge des soufis critiques à l'égard des pouvoirs, c'est-à-dire de ceux qui ont été indifférents au prestige et aux séductions, étrangers à leurs temps corrompus.

14 Exposons brièvement les caractéristiques historiques des trois grands islamismes marocains. 


\section{1 - Ac-chabiba al Islamiya}

15 Le leader fondateur, Abdelkrim Mouti', n'est pas un 'alim. Enseignant, c'est un ancien militant de l'Union Nationale des Forces Populaires (principal parti de la gauche marocaine à l'époque) qu'il a quittée pour s'identifier et suivre Sayyed Qotb ${ }^{16}$. Il en adopte le livre Jalons sur la route (Ma'alim fi at-tariq) et en fait la référence idéologique de son organisation naissante, la Chabiba. Mouti' fonde son mouvement islamiste en 1969, au lendemain de la défaite du nationalisme arabe de 1967 et surtout après la constitution des premier noyaux du mouvement marxiste (23 mars, Ila al-Amam, Parti de la Libération et du Socialisme).

L'analyse de la Chabiba doit distinguer entre son volet clandestin et violent d'un côté, et son volet légal et apostolique de l'autre. En effet, en tant que mouvement social clandestin, la Chabiba existe depuis 1969, c'est le Mouvement de la Chabiba Al-Islamiya. Quand au volet institutionnel, il est incarné par l'Association de la Chabiba al Islamiya, dont les statuts sont déposés en 1972. Ce clivage entre le mouvement et l'association illustre et infirme à la fois l'effet Mühlmann, que R. Lourau résume ainsi : «l'institutionnalisation d'un mouvement social est rendue possible par l'échec de la prophétie dont était porteur le mouvement ${ }^{17}$ ». Cet effet loi stipule que, dans une première phase, le mouvement social commence par être agité et agitateur grâce à la rencontre d'un groupe avec une idéologie chaude et mobilisatrice. Dans une deuxième phase, la récupération idéologique du mouvement et la non réalisation de son message prophétique, autrement dit son échec, finissent par le transformer en institution officielle, en interlocuteur politique, essayant de se réaliser partiellement à l'intérieur du système, par la négociation.

Le passage de la Chabiba du statut de mouvement à celui d'association illustre donc cet effet Mühlmann. Mais dans le cas de la Chabiba, l'institutionnalisation sous forme d'association ne signifie pas la rupture totale avec l'agitation et la violence. En effet, le mouvement n'a pas disparu, il a continué d'exister parallèlement à l'association. Il arrivait même que les membres de l'association ne connaissent pas ceux du mouvement et vice versa. Par ce côté, l'évolution de la Chabiba infirme l'effet Muhlmann. L'institutionnalisation a été partielle et n'a pas extirpé le recours à la violence.

18 A. Mouti' a donc constitué une association à caractère religieux et éducatif, sans rapport avec l'action politique, et qui revendique la légalité. Dans son discours adressé au pouvoir, il affirme que le moyen d'action de cette association n'est que l'explicitation de la foi islamique. Il ajoute que la Chabiba «n'est qu'un groupe de musulmans et non le (seul) groupe des musulmans». Par conséquent, elle ne prétend pas monopoliser l'islam. Pour rendre ce discours crédible et rassurant, A. Mouti' le publie dans Al-Mithaq ${ }^{18}$, le journal de la vénérable et conservatrice Ligue des Oulémas du Maroc (voir plus loin).

En même temps, tout en se posant comme une association pacifiste de prêche, la Chabiba est d'un radicalisme extrême: elle accuse société et pouvoir de vivre dans la Jahiliya (période d'ignorance préislamique). Elle prône le djihad (guerre sainte) contre eux, par la violence, afin de rétablir l'ordre de Dieu. Le mouvement de la Chabiba, Fassil al-Djihad, incarne cette dimension clandestine. À travers son action clandestine et violente, A. Mouti' vise en principe le pouvoir et la gauche. Mais en pratique, la violence de la Chabiba n'atteint que la gauche, et plus précisément l'USFP, « ce parti des impies » qui « sécrète l'athéisme ». En 1975, la Chabiba assassine Omar Bengelloun, l'un des leaders de l'USFP. Kamal Ibrahim, le vice-président de la Chabiba, est arrêté. Quant à Mouti', accusé d'être 
impliqué dans l'assassinat, il fuit le Maroc avant d'être condamné en 1980 par contumace à la prison à vie. Après cette condamnation, Mouti' déclare ouvertement son opposition au régime dans sa revue Al- Moujahid en mars 1981. Un mois après (avril 1981), la direction de la Chabiba décide de l'expulser de ses rangs. La rupture est consommée. A. Mouti' se consacre alors entièrement à l'organisation du Bataillon du Djihad, groupuscule clandestin et violent. En 1984, il publie La révolution islamique : destin du Maroc actuel ${ }^{19}$.

D'autres groupuscules islamistes au Maroc se réclament de cette ligne islamiste révolutionnaire. Il s'agit notamment de : l'Organisation des Combattants au Maroc ${ }^{20}$ fondée par Abdelaziz Naamani, membre de la Chabiba, l'Organisation des Soldats de Dieu ${ }^{21}$, le Parti de la Libération islamique ${ }^{22}$, l'Organisation de la Guerre Sainte ${ }^{23}$, le Mouvement de la Jeunesse Islamique Révolutionnaire ${ }^{24}$. Selon A. Lamchichi, « hormis (ces) quelques groupuscules sans grande influence et sans véritable assise sociale dans le pays, qui ont opté pour la violence, l'essentiel des courants et des leaders de l'islamisme au Maroc ont opté pour l'action légale, dans le cadre d'associations culturelles et cultuelles, et la pression sur le régime et la société ${ }^{25}$ ».

21 La nouvelle direction de la Chabiba renonce à la ligne révolutionnaire ainsi qu'à l'appellation Chabiba. Elle s'institutionnalise d'abord dans l'association Al Jamấa alIslamiya, avant de prendre son nom actuel Harakat Al-islah wa at-tajdid, laquelle ne fait aucunement allusion à l'islamisme. Les notions d'al-islah (réforme) et d'at-tajdid (renouvellement) ne sont pas spécifiquement associés à l'islam dans l'imaginaire politique des musulmans.

\section{2 - Al-Jamâ'a al Islamiya / harakat al-islah wa at-tajdid}

La nouvelle direction rejette la clandestinité, la révolution, l'extrémisme et la violence sous toutes ses formes ${ }^{26}$. Elle estime qu'au Maroc les islamistes sont obligés de sortir de leur isolement en participant à la vie politique. Le triomphe de la Loi islamique doit emprunter ce chemin. "La participation politique à laquelle nous appelons consiste essentiellement à semer, dans le peuple, l'espoir de la possibilité de la réforme et du changement vers l'Islam, et ce d'une manière pacifiste qui adopte le dialogue ${ }^{27} . .$. ».

À partir de 1983, la nouvelle direction adopte la forme institutionnelle associative, la Jamấa al Islamiya, à Rabat d'abord avec A. Benkirane (professeur de physique), à Casablanca ensuite avec Al-Othmani (médecin). Selon Benkirane, les «nombreux mouvements islamistes qui choisissent l'organisation clandestine n'ont aucune raison valable pour justifier ce choix, car ils ne sont pas des terroristes, ils ne planifient pas un coup d'état, ils ne possèdent pas d'armes. Ce sont seulement des groupes de jeunes religieux ayant des représentations erronées sur le régime qu'ils considèrent comme un régime policier qui recense leurs faits et gestes ${ }^{28} \ldots$ ".

Tout à sa quête de reconnaissance et de légalité, A. Benkirane envoie un télégramme au roi dans lequel il demande la normalisation du statut de la Jamấa Al Islamiya (29 novembre 1985), puis une lettre au ministre de l'Intérieur (17 mars 1986) dans laquelle il critique Mouti' et proclame la rupture de sa Jamâ' $a$ avec la Chabiba. Il affirme explicitement que la Jamâ'a Al Islamiya n'est pas l'ennemie du régime de la monarchie constitutionnelle. Il reconnaît que celle-ci est fondée sur la légalité religieuse et la profondeur historique. Plus encore, en annonçant dans un communiquée ${ }^{29}$, qu'elle se nomme désormais Harakat Alislah wa at-tajdid, la Jamâ'a Al Islamiya entend faire savoir qu'elle gomme toute consonance islamique. Le substantif Jamâ’a (communauté, à connotation islamique) et le qualificatif 
islamiya, monopoliste, sont supprimés pour laisser place aux termes Islah (réforme) et Tajdid (renouvellement), lesquels appartiennent au lexique de la pensée politique arabe de la Nahda (Renaissance arabe du XIX ${ }^{\mathrm{e}}$ siècle).

Malgré la présence du terme harakat (qui signifie mouvement) dans la nouvelle appellation, le passage de la Chabiba Al Islamiya à Harakat Al-islah wa at-tajdid confirme cette fois l'effet Mühlmann. L'échec de la Chabiba révolutionnaire (mouvement) se reflète dans la volonté de participation politique de Al-islah wa at-tajdid (association). Certes, affirme A. Benkirane le 21 mai 1996, «l'État n'a pas encore reconnu la légalité de notre association... l'État nous tolère... nous n'avons pas le droit de mettre notre nom sur notre siège ${ }^{30} \ldots »$.

Devant la persistance de sa non reconnaissance et dans sa recherche d'une organisation politique qui lui permette la participation, Al-islah wa at-tajdid se rapproche idéologiquement du parti de l'lstiqlal. D'idéologie salafite (revendications d'interdiction de la vente des alcools et du vendredi comme jour chômé à la place du dimanche...), celui-ci a toujours tenté d'assimiler les islamistes. De son côté, A. Benkirane reconnaît que «le parti de l'lstiqlal est beaucoup plus proche de nous que des autres partis de la gauche ${ }^{31}$ " avec lesquels il se retrouve dans la Koutla ${ }^{32}$. Cependant, la force de l'lstiqlal et son réformisme inspiré d'Allal El Fassi ne sont pas un cadre favorable à l'expression des thèses islamistes populistes. L'lstiqlal exprime surtout les intérêts de la bourgeoisie citadine traditionnelle.

C'est la raison pour laquelle l'association Al-islah wa at-tajdid s'est vue contrainte de chercher une organisation politique avec laquelle elle puisse coopérer à armes égales. Le Mouvement Populaire Constitutionnel et Démocratique (MPCD, fondé en février 1967) semble être l'organisation politique indiquée. C'est le cadre dans lequel milite un grand nombre d'islamistes qui préfèrent agir dans la légalité. Pourquoi ?

La rencontre entre le MPCD d'Abdelkrim El-Khatib et Harakat Al-islah wa at-tajdid s'opère sur une base commune: l'adoption de l'islam comme référence suprême. Dès 1972 en effet, le MPCD affirme, par l'intermédiaire de A. Khatib - qui répond à la lettre du roi du 23 septembre 1972 adressée aux partis politiques - qu'il est impossible d'envisager une réforme radicale et totale de la société marocaine sans retour à la religion de Dieu. A. Khatib invite le roi à « consolider les piliers de l'Islam dans le pays, dans les formes du pouvoir politique, dans notre pensée, notre comportement, nos lois, notre enseignement, notre administration et notre magistrature ${ }^{33} »$. En 1984. lors de la campagne électorale à l'occasion des élections législatives, Khatib explique encore que la crise générale que connaît le Maroc est due à l'abandon de la voie islamique par le pouvoir. Cette conviction pousse A. Khatib à soutenir l'Iran ${ }^{34}$ dans sa guerre contre l'Irak. À ses yeux, ce dernier est un pays laïc. Toujours sur cette lancée, Khatib défend les étudiants islamistes en condamnant la gauche marocaine.

Tout cela n'a donc pas manqué d'attirer Harakat Al-islah wa at-tajdid. Ainsi, lors de son interview le 21 mai 1996, A. Benkirane reconnaît que son association est « en train de travailler avec le Dr Khatib pour réorganiser le parti (du MPCD)...(Khatib) est la seule personnalité politique qui nous a reçu et qui a accepté de travailler avec nous sans conditions. Nous sommes d'accord avec lui sur ces principes: l'Islam, la monarchie constitutionnelle et la non-violence. De plus, le Dr Khatib est un homme propre qui partage avec nous notre conception islamique... Nous pensons mener notre action politique dans (ce) cadre $^{35}$... ». 
30 Cette rencontre entre le MPCD et Harakat Al-islah wa at-tajdid est consacrée lors du congrès extraordinaire du MPCD tenu le 2 juin 1996. À cette occasion, le MPCD élit trois membres du bureau exécutif de Al-islah wa at-tajdid comme membres de son propre comité exécutif (7 membres). Le Dr Khatib, lui, conserve son poste de secrétaire général du parti.

31 Ainsi, il ressort de la métamorphose du mouvement de la Chabiba en une association légaliste, Al-islah wa at-tajdid, que l'islamisme marocain perd de sa dimension révolutionnaire. Pour A. Benkirane, « le régime monarchique a la légitimité islamique, il est l'arbitre et le ciment de l'unité nationale ${ }^{36} »$.

32 Ce processus résume-t-il le devenir des islamismes marocains dans leur totalité ? L'association Al-'Adl wa al-lhsan illustre la non généralisation de l'effet Mühlmann à tous les islamismes marocains.

\section{3 - Al-'Adl wa al-Ihsan}

33 Le fondateur de l'association est A. Yassine ${ }^{37}$. Également enseignant, il est d'abord membre de la confrérie Bûchichiya dans laquelle il reste six ans. Il la quitte à la suite d'un différend autour des méthodes d'action avec le shaykh de la confrérie, dont il veut même prendre la direction.

34 Après cette rupture, il adresse, en 1974, une lettre ouverte ${ }^{38}$ au roi, dans laquelle il joue le rôle du savant qui montre le chemin au prince égaré. Il est enfermé dans un asile psychiatrique. En février 1979, Yassine fait paraître le premier numéro de la revue Al Jamâ'a et en 1982, il fonde l'association Al-Jamâ'a qui n'est pas reconnue par les autorités (février 1983) en raison de ses activités politiques. Dès avril 1983, il dépose les statuts d'une nouvelle association, Jamâ'at al Jamấa al Khaïriya, en mentionnant explicitement dans ses statuts son caractère politique. Pour Yassine, la dégradation du pays, la propagation des maladies sociales, le recul de la religion dans la vie motivent la naissance de l'association Al-'Adl wa al-Ihsan. En raison de ces motifs, les statuts de l'association lui confèrent volontairement un caractère politique, « afin que le champ de la da'wa soit plus large et plus souple ${ }^{39}$ ». Yassine appelle à la participation politique, qui est appel à Dieu, dont le devoir est "l'instauration de l'État califal unifié ${ }^{40}$ ». L'association a un caractère public, elle veut éviter la violence dans l'action et dans le discours. Son but est « d'amener les adhérents et les gens du peuple à prendre conscience de leurs droits politiques ».

À partir de 1987, l'association adopte le slogan Al-'Adl wa al-Ihsan (Justice et bienfaisance) et se fait appeler par ce nom. Selon Yassine, l'adoption de la notion d'Adl, coranique certes, exprime la dimension étatique de son association et en appelle à la justice sociale, fonction de l'État islamique par excellence. D'un autre côté, la notion d'Adl détruit le monopole politique exercé par la gauche sur la question sociale. Pour Yassine, il n'est pas question de laisser la gauche exprimer et défendre seule les intérêts des faibles, des pauvres et des exclus. La notion coranique des Mustad'afûn (affaiblis par la société) habilite également les représentants de la pensée islamique à les représenter. Al-'Adl wa al-Ihsan et gauches marocaines expriment donc les frustrations et les colères des mêmes couches sociales. Mais si la gauche appelle à la radicalisation de la lutte des classes, Al-'Adl wa al-Ihsan, par le biais de la notion d'Ihsan, appelle au contraire à l'entraide, à la solidarité, à la charité au sens noble. Al Ihsan est une notion coranique qui représente la méthode islamique pour venir à bout de l'animosité entre les classes sociales. Al-'Adl wa alIhsan est donc une appellation qui se substitue à l'appellation Jamâ'at al Jamâ'a al Khaïriya. 
Même si dans les deux cas le terme islamique n'apparait pas, on reste dans un système de référence islamique. Jamầa (communauté, groupe), khaïriya (bienfaisante), 'adl (justice) et Ihsan (charité) sont des notions qui appartiennent toutes au vocabulaire islamique. On trouve même les deux dernières dans le Coran. Le changement de nom semble donc renforcer ici l'orientation islamiste, dans la mesure où, d'une part la notion de Jamâ'a est maintenue, et où, d'autre part, les slogans islamistes d"Adl et d'Ihsan sont promus au rang de marqueurs et d'identité institutionnelle.

À la différence de Harakat Al-islah wa at-tajdid qui se réclame uniquement d'un islamisme apostolique qui n'exclue personne de l'islam (intégrationnisme), Al-'Adl wa al-Ihsan prône aussi, outre l'islamisme apostolique, l'exclusion et le djihad contre les faux musulmans de l'intérieur. En ce sens, elle est une synthèse de l'intégrationnisme et de l'exclusion. Da'wa et contestation politique vont de pair. Certes, ses références soufies devraient la pousser à s'opposer au pouvoir, non pas pour prendre le pouvoir, mais pour dire que l'islam véritable consiste à renoncer à toute forme de pouvoir. En recherchant le pouvoir à travers la déligitimation religieuse du régime établi, Al-'Adl wa al Ihsan rompt avec cet idéal soufi et semble s'acheminer vers la violence comme conséquence de l'exclusion. Mais d'un autre côté, Yassine critique Sayyed Qotb qui, selon lui, se limite au djihad, sans compléter cette violence nécessaire par une action éducative. La da'wa éducative est incontournable.

De cette manière, Yassine reproche aux soufi de s'arrêter au stade de la da'wa, et aux activistes de ne faire que le djihad. Al-'Adl wa al-Ihsan se veut la synthèse des deux : par le ' Adl, elle appelle au djihad, par l'Ihsan, elle appelle à l'éducation. Soldats le jour, moines la nuit, tels sont les militants de Al-'Adl wa al Ihsan. En cela, Yassine veut que son association ne soit l'imitation ni d'une association traditionnelle (confrérie ou secte), ni d'une association moderne, mais une synthèse originale entre l'ancien et le nouveau d'une part, et entre les différents visages partiels et antagonistes de l'islamisme actuel d'autre part.

Cela étant, les écrits de Yassine, référence idéologique suprême de Al-'Adl wa al-Ihsan, tentent également de fonder une base théorique unique pour l'ensemble de l'islamisme marocain. Malgré l'idéal du retour à l'État califal, Yassine impose à chaque islamisme particulier, dans une première phase, de réaliser une unité première avec les autres islamismes de l'État national. L'existence de plusieurs islamismes au Maroc et dans chaque pays islamique est une source de faiblesse: «la priorité des priorités est de constituer une association par pays... » affirme-t-il ${ }^{41}$. Là, le passage de la première à la seconde appellation de l'association semble trahir cet idéal : la Jamâ'at Al-'Adl wa al-Ihsan n'est plus cette sorte de fédération des Jamâ'at que laissait entendre la première appellation, Jamâ'at Al Jamâ'a al Khaïriya. Le caractère totalitaire de la première appellation a disparu.

\section{II - Les autres de l'islamisme marocain}

Pour identifier les autres de ces trois visages de l'islamisme marocain, il convient de se situer dans leur perspective propre, à partir de l'analyse qu'ils font de leur environnement social. Quelles notions les islamistes marocains investissent-ils dans leur analyse de la société et de l'État marocains? Constate-t-on des différences entre les sociologies spontanées de la Chabiba, d'Al-islah wa at-tajdid et d'Al-'Adl wa al-Ihsan? Sur quels autres débouchent ces sociologies participantes, chaudes et prosélytes? 


\section{1 - La sociologie islamiste}

40 Le «théoricien » de la Chabiba, A. Mouti', à la suite de l'égyptien Sayyed Qotb, investit la notion de Jahiliya (ignorance pré-islamique) pour décrire la société et l'État marocains. Par cet emploi, il signe son radicalisme et sa volonté d'exclure tous les autres marocains de l'islam. Le terme est fort dans la mesure où la Chabiba accuse tous les autres marocains de non-islam, c'est-à-dire de vivre comme aux temps pré-islamiques marqués par l'ignorance de la Loi Divine (charîa).

41 C'est une notion moins forte, celle de déviance (inhiraf), qu'investit Al-Isalh wa at-tajdid du temps où elle s'appelait la Jamâ'a al-islamiya ${ }^{42}$. La déviance indique que la communauté est musulmane, même sans suivre la voie tracée par l'islam. Cette déviance est à la fois sociale et étatique.

42 Au niveau de la société, la déviance est perceptible dans les croyances, les rites et les pratiques sociales. Les croyances des Marocains sont dominées par le culte des saints, la foi accordée aux phénomènes de voyance et la remise en question des dogmes (existence de Dieu, jour du jugement dernier...). L'inobservance des rites religieux est également patente : abandon de la prière (pilier de la religion) et de la zakat (aumône légale), car, en instituant un impôt d'origine positive, l'État marocain n'oblige pas le Marocain musulman à verser la zakat. De son côté, le musulman ne verse plus spontanément cette aumône légale. Le mois de ramadan, mois de jeûne censé être un mois de méditation spirituelle, connaît l'explosion des désirs et des plaisirs charnels. Quant au pèlerinage à la Mecque, il est devenu une pratique à caractère essentiellement ostentatoire. En ce qui concerne les pratiques sociales, le mensonge entre musulmans s'est répandu, tout comme l'arnaque, la corruption et le népotisme. De leur côté, l'expansion de la mixité et du dévoilement de la femme provoquent des maux sociaux tels que la séduction, l'adultère, la prostitution, les enfants naturels, le divorce et les MST. Enfin, la société marocaine est connue pour sa grande consommation d'alcools et de drogues. Tous ces fléaux sont en expansion.

Pour la Jamâ'a al Islamiya, la déviance de l'État marocain est imputable à la déviance de sa politique générale et de ses politiques particulières. Dans le domaine de l'enseignement d'abord, on assiste à la dissociation entre instruction et éducation (l'instruction sans vertu), à une arabisation timide et à l'encouragement éhonté de la francophonie. La faiblesse des cours de sciences islamiques dans les programmes en est un indice complémentaire, au même titre que la mixité sexuelle sans aménagements dans tous les cycles de l'enseignement. Le champ médiatique est dominé par les chansons, les sports, les films et les publicités. Dans le domaine de l'économie, l'usage du riba (prêt à intérêt et/ou spéculation profitable et non productive), les dettes extérieures, la baisse du pouvoir d'achat des citoyens, l'exploitation des ouvriers, l'importation du modèle de la société de consommation témoignent de la déviance de l'État par rapport à la ligne islamique. En ce qui concerne la juridiction, le droit islamique est remplacé par le droit positif, à l'exception du code du statut personnel (code de la famille). Mais même celui-ci est l'objet d'une mobilisation qui tend à le réformer, voire à le supprimer. Quant à l'administration, celle-ci autorise l'urbanisation pathogène, la vente des vins et des alcools, l'organisation des jeux de hasard. Sur ce dernier point, « le ministre du tourisme a expliqué que, pour encourager le tourisme, il allait permettre l'ouverture de cinq casinos au Maroc : ça non! » s'écrie A. Benkirane ${ }^{43}$. 
Cette sociologie spontanée critique, centrée sur la notion de déviance, débouche sur le constat de la nécessité de répandre la da'wa afin de participer et de consolider les efforts officiels. La Jamâ'a Al Islamiya/Harakat Al-islah wa at-tajdid reconnaît que l'État marocain, malgré sa déviance, fournit des efforts en vue d'islamiser la société. Sa critique n'est pas radicale comme l'était celle de son association-mère, la Chabiba. La critique n'atteint pas ici le seuil de la contestation politique.

Quant à Yassine, le leader de Al-'Adl wa al-Ihsan, plus le temps avance, moins il emploie la notion de Jahiliya. La notion est en effet subversive et radicale: elle accuse les autres d'impiété et légitime leur takfir (excommunication). Présente dans ses premiers écrits, notamment dans La lettre ouverte au $R i^{44}$, cette notion cède progressivement la place à celle de fitna. Yassine n'interprète pas la fitna comme jahiliya, comme le fait Qotb, car chez celui-ci, la fitna est tantôt jahiliya d'origine intérieure, tantôt persécution extérieure (sionisme, communisme athée...). Pour Yassine, l'islam ne donne le droit à aucun musulman de déclarer les autres musulmans kouffar (impies), implicite dans la notion de jahiliya. "Si nous jugeons que nos sociétés sont ignorantes (pré-islamiques), en dehors de la religion de Dieu, nous devenons impies par nous-mêmes... nous sommes (seulement) des musulmans individualistes en état de sédition $\left(\right.$ maftunin $\left.^{45}\right)$ ». Nous proposons de traduire fitna par sédition: «quand le juste est refoulé et l'injuste répandu, quand la violence remplace la force, et quand la coopération (entre musulmans) et l'amour cèdent la place aux tribalismes, l'islam appelle cela fitna. C'est un concept qui signifie à la fois crise, sous-développement, instabilité, désordre et athéisme ${ }^{46} \ldots$ ». L'un des aspects de cette fitna est la «dépravation sexuelle (qui) a fait du Maroc un nid de prostitution internationale $e^{47}$ ». Un autre aspect réside dans cet «argent qui permet à une faction de jouir dans le gaspillage, au détriment de l'économie de la Umma ${ }^{48}$... ».

Pour venir à bout de la sédition, Yassine avance que « l'Islam vrai est notre seul sauveur ${ }^{49}$ ». Mais jamais, continue-t-il, il ne sera fait appel à la violence, car l'islam ne s'est pas instauré par la violence. Encore une rupture avec Qotb. Yassine prône la méthode prophétique, fondée sur la douceur et la sagesse, afin d'organiser et de répandre la da'wa. Venir à bout de la dégénérescence morale, des hérésies et du pourrissement politique et administratif, voilà les objectifs du djihad qu'il propose. Contestation politique certes, mais sans le recours à la violence. L'islamisme doit veiller alors à produire une opinion publique islamique par la réhabilitation de l'islam primitif comme seule réalisation historique de l'islam, et comme seul modèle normatif de l'État. La motivation majeure qui pousse l'islamisme vers la conquête du pouvoir en vue de restaurer l'État califal, c'est le désir d'instaurer l'égalité et d'éliminer les privilèges, par le moyen de l'lhsan.

Trois traits majeurs nous semblent caractériser la sociologie spontanée de l'islamisme marocain.

C'est d'abord une sociologie qui parle de la société marocaine comme d'un groupe homogène ne connaissant pas des variations d'opinion et de comportement en fonction de l'âge, du sexe, du statut socio-professionnel, du milieu de résidence... Par exemple, cette sociologie n'établit pas de façon exacte le pourcentage de l'abandon de la prière et du ramadan, ni ne dresse le profil social des Marocains non pratiquants. ${ }^{50}$

Ensuite, c'est une sociologie prophétique dans la mesure où elle propose une vision d'avenir orientée vers le passé et un idéal politique fondé sur le modèle de l'État califal.

C'est enfin une sociologie qui désigne les autres, c'est-à-dire les adversaires, les ennemis à combattre, responsables de jahiliya, de la déviance et de la sédition. Ces autres sont à 
renverser, à corriger, à combattre. C'est donc une sociologie activiste, militante. Quels sont ces autres?

\section{2 - L'Autre et les autres}

51 D'un côté, en raison de son holisme, la sociologie islamiste semble incapable de fournir une sociologie politique différentielle : en deçà du politique, pour elle, tous les acteurs politiques se confondent dans un même Autre. Roi et Makhzen, partis politiques de l'administration, partis politiques nationalistes et démocratiques, partis en retrait, groupuscules gauchistes, syndicats et organisations féministes ne sont pas, pour la sociologie islamiste, des acteurs distincts dont il conviendrait d'analyser les statuts et les rôles sur l'échiquier socio-politique. Pour l'islamisme marocain, la classe politique, composée des faux musulmans de l'intérieur, constitue un tout homogène qui trahit l'islam.

De l'autre côté, la sociologie islamiste distingue l'Autre principal et immédiat (le Makhzen, pouvoir monarchique central) des autres, périphériques ou extérieurs. L'Autre est donc différencié, non sur la base d'une analyse objective et sereine, mais à partir d'une production d'images et de stéréotypes arbitraires ${ }^{51}$. Cette déformation de l'Autre est de nature politique, elle est l'arme fondamentale que la propagande islamiste utilise pour faire de l'islamisme le seul moyen politique de sauver la société de ses «autres", de ces autres politico-religieusement "dangereux ». Mais en étant lui-même à la fois uni et éclaté, l'islamisme ne peut que produire un Autre tout aussi uni et tout aussi éclaté.

\section{a-Extériorité et périphérie}

Pour la Chabiba al Islamiya, ces autres étaient le maoïsme, le marxisme et le mouvement hippie. Et selon Libération ${ }^{52}$, la Chabiba a été créée en vue de liquider les politiques et les intellectuels considérés comme les adversaires de l'islam.

Al-islah wa at-tajdid s'en prend essentiellement aux associations féminines-féministes marocaines et aux autres de l'extérieur ou aux autres périphériques de l'intérieur. Femmes et Occident sont ces autres: les premières en raison de leur différence irréductible, le second en raison de son extériorité dominante.

À l'égard des féministes, Benkirane admet en effet que "nous avons affronté les prétentions qui ont voulu faire de l'ijtihad dans la Mûdawwana sans considérer la référence islamique et en appelant à changer la charîa de l'islam en matière d'héritage et de mariage... mais nous serons toujours pour le dialogue ${ }^{53}$ ». « Nous avons été, continuera-til ailleurs, contre le million de signatures que voulaient réunir certaines organisations féministes pour changer la Mûdawwana dans un sens que nous avons jugé trop laïc ou, disons, trop laïcisé ${ }^{54} »$. La constitution d'une Organisation du Renouvellement de la Conscience Féminine, d'inspiration islamique, est une manière de combattre cet autre qu'est le féminisme éclairé, dépendant des partis politiques comme l'USFP, le PPS et l'OADP. Parmi les objectifs de cette association féministe islamiste naissante, "montrer l'inadéquation du modèle occidentalisant à la femme musulmane, et son aspect dangereux tant ici-bas que dans l'au-delà ${ }^{55} »$. Al-islah wa at-tajdid entreprend ici une formation religieuse auprès des femmes, celles-ci étant les responsables de l'éducation des générations futures ${ }^{56}$. 

afin d'ourdir des complots impérialistes contre les îlots de l'islamisme), un numéro de Arraya $^{57}$, le porte-parole de Al-islah wa at-tajdid, désigne comme autres de l'extérieur :

58 - l'Observatoire Géopolitique de la Drogue (Paris) qui, dans son rapport sur le Maroc, affirme que «certains juristes du nord du Maroc ont élaboré une fetwa qui stipule que la religion ne s'oppose pas à la culture (du cannabis) qui assure la survie des pauvres... à partir du principe que la nécessité suspend les interdits ». Le faqih Abdellatif Guessous estime que c'est là " une fetwa diabolique, inspirée des Croisades, sioniste ${ }^{59}$ ", c'est selon lui, une mise en scène effectuée par le champ médiatique occidental afin de salir l'image de l'islam.

59 - Israël : « il n'est pas normal que nous entrions dans des relations avec Israël alors que nos relations avec l'Iran sont mauvaises ${ }^{60} »$, rappelle Benkirane. Le laxisme d'Israël relatif aux lois de naturalisation et aux crimes du blanchissement de l'argent sale est dénoncé.

60 Ainsi, l'image de ces autres met en évidence leur injustice, impureté, matérialisme, sionisme, utilitarisme...

61 Quand aux autres de Al-'Adl wa al-Ihsan ${ }^{61}$, ils sont essentiellement à l'intérieur. Ce sont :

62 - les confréries avec lesquelles il faut rompre, et plus précisément avec la Bûchichiya qui connaît un renouveau et qui exercerait selon P. Lambert, « une très forte attraction sur la jeunesse étudiante et ouvrière ${ }^{62} \%$.

63 - les fogaha (jurisconsultes) anciens et nouveaux (dont les jugements ne lient pas l'association);

64 - nos frères musulmans (au sens large) qui reconnaissent le pouvoir établi injuste, et par rapport auxquels il faut se démarquer ;

65 - le pouvoir qui doit appliquer la Loi divine ;

66 - les partis politiques qui doivent mettre les intérêts de la communauté au-dessus de leurs intérêts propres;

67 - le marché de la gauche où l'université est une place forte à marchander avec le pouvoir ;

68 - les ouléma qui doivent devenir moins utilitaristes et moins peureux du pouvoir, leur peur étant illusoire ;

69 - le peuple, vivant dans la pauvreté, l'ignorance, l'occidentalisation, et la fitna.

70 Le jeu de ces autres auxquels s'opposent les islamistes dans le champ politico-religieux, est réglé et dirigé par le Makhzen. C'est donc le Makhzen qui, pour les islamistes marocains, est l'Autre par excellence, au sens freudien ci-dessus indiqué : étranger au pays parce qu'il trahit l'islam de sa population, manipulateur, répressif, source de peur... Le Makhzen, cette inquiétante étrangeté, diraient les islamistes.

\section{b - Le Makhzen, ce grand Autre}

71 L'étude de ce grand Autre est incontournable pour comprendre l'islamisme comme un phénomène réactionnel dont ses sources seraient à trouver dans une causalité politique intérieure. L'islamisme est réactionnel dans la mesure où l'islam joue un rôle capital dans l'auto-définition et le renforcement du Makhzen au lendemain de l'indépendance. 
72 En effet, l'article 1 de la constitution définit le Maroc comme une monarchie islamique : roi et islam sont au-dessus de tout, au-dessus de la constitution elle-même. Les deux se représentent et se défendent mutuellement. Pour cette raison, l'article 19 de la Constitution définit le roi comme le Commandeur des croyants. Par ailleurs, le roi se présente comme le porte-parole des revendications du monde musulman, il est le président du Comité pour la Libération d'Al Qods (Jérusalem). Il est enfin le seul chef d'un État musulman qui a reçu le pape.

73 L'auto-définition par l'islam est une arme à double tranchant : d'une part, elle octroie une légitimité religieuse au pouvoir politique du roi et le renforce, d'autre part, elle oblige le roi à justifier ses politiques aux yeux de tout musulman, de tout détenteur d'une forme de capital islamique (science, grâce ou noblesse), et spécialement devant les détenteurs de la science, les ouléma. Ceux-ci sont non seulement appelés à reconnaître le caractère islamique des agissements du roi et des politiques de l'État, mais à reconnaître surtout que la personne du roi, Commandeur des Croyants, est conforme aux conditions de l' imama (fonction de commander les croyants). Cette reconnaissance, première, se nomme bei'a (allégeance et reconnaissance). La bei”a des ouléma est plus importante que celle des autres corps de l'élite (khassa) dans la logique politique de l'islam: les ouléma sont les seuls à savoir s'il y a conformité aux conditions islamiques du commandement des croyants.

74 L'islamisme marocain consiste donc, entre autres, à dire que la fonction de commander les croyants n'est pas remplie, ou que les politiques suivies ne sont pas conformes à l'islam. Mais une telle critique n'est pas forcément islamiste, dans le sens où elle n'est pas rattachable uniquement aux mouvements islamistes stricto sensu. Dans le cadre de cette critique religieuse adressée au Makhzen, deux dates en effet sont à retenir : 1962 et 1974.

En 1962, lors du référendum constitutionnel, Larbi Al Alaoui adresse une critique religieuse à rencontre du projet de constitution. Selon ce shaykh, ce projet « porte atteinte aux principes du droit musulman par l'adoption de l'hérédité monarchique et l'institution d'un pouvoir législatif ${ }^{63}$ ». Cette critique n'attaque pas la personne du roi et ne l'accuse pas personnellement de trahir l'islam. Elle s'attaque plutôt à la nature du système politique que la constitution de 1962 tente d'établir. Pour le shaykh al Islam, l'islam ne reconnaît ni l'hérédité comme un moyen légal de transmettre la fonction de commander les croyants ni l'institution d'un parlement producteur de lois. La critique n'est pas islamiste dans la mesure où le shaykh exprimait à la fois l'idéal républicain de la gauche à l'époque et la résistance des ouléma au processus de modernisation politique qui les marginalisait de la production des lois. A posteriori, cette critique peut être taxée de critique islamiste sans islamisme. Rappelons ici que le shaykh Larbi Al Alaoui parlait au nom de l'aile islamique de l'Union Nationale des Forces Populaires (parti de gauche).

Cette critique pré-islamiste de la gauche marocaine fait sentir au pouvoir central la nécessité de contrôler les ouléma. Dès 1963, par le biais du ministère des Awqaf et des Affaires islamiques ${ }^{64}$, le pouvoir va procéder à la transformation des ouléma en fonctionnaires du Makhzen. L'officialisation de l'université Qarawiyine comme institution autonome de l'enseignement supérieur et la «dissémination » de ses facultés à travers quelques grandes villes du Maroc (Fès, Tétouan, Marrakech et Agadir) est symbolique. D'une part, elle témoigne d'une volonté de traditionnalisation, face au processus de modernisation incarné par la seule université moderne de l'époque, l'université Mohamed V de Rabat. D'autre part, cette autonomisation de la Qarawiyine, tout en étant un traitement de faveur à l'égard des ouléma qui leur garde une distinction (par rapport 
aux intellectuels modernes), est surtout une manière de la fonctionnariser afin d'empêcher les ouléma-fonctionnaires de critiquer l'État en ce qui concerne la production et la commercialisation du vin, le vêtement féminin, l'existence de discothèques... Ce sont là des phénomènes qui assurent des revenus financiers et symboliques à l'État tout en étant en contradiction avec les lois de la Chari'a. Il s'agit donc d'amener les ouléma à ne pas s'en mêler en les transformant en fonctionnaires dépendants et dociles. D'une manière plus claire encore, la fondation de Dar al Hadtih Al Hassaniya en 1964 va dans le même sens : c'est une institution de la formation des ouléma-cadres (de l'État).

Les ouléma de la Qarawiyine s'organisent dans la Ligue des Ouléma du Maroc (fondée en 1961 à Tanger ${ }^{65}$ ), ceux de Dar El Hadith Al Hasaniya se regroupent dans l'Association des Lauréats de Dar El Hadith el Hassaniya (1967). Les ouléma des deux institutions sont, à quelques exceptions près, au service des politiques du pouvoir. Dans un premier temps, il leur est explicitement demandé de ne pas se mêler de politique, et de ne pas condamner par exemple la libéralisation des mœurs sexuelles sous le prétexte de la prescription islamique al-amr bi al-maârouf wa en-nahy 'ani al-monkar ${ }^{66}$ (le commandement du bien et la réprimande du mal). En d'autres termes, leur fonction est de cautionner la politique libérale de l'État. Ainsi, à travers le contrôle des ouléma transparaît la volonté de fonctionnariser ces intellectuels qui seuls sont habilités à légitimer islamiquement les politiques du pouvoir. En conséquence, il est normal que, pour le pouvoir, seuls ces ouléma domestiqués soient habilités à faire de l'apostolat ( $\left(a^{\prime} w a\right)$, à éduquer les masses, à définir le véritable islam en dernière analyse.

Douze ans après la critique pré-islamiste de Larbi Al Alaoui, A. Yassine adresse au roi une lettre-sermon qui est, cette fois-ci, une critique islamiste au sens strict, et s'inscrit dans le paradigme islamiste. Sous la plume de Yassine, l'islam devient un instrument de déligitimation religieuse des politiques de l'État et du roi lui-même.

La lettre de A. Yassine (1974) symbolise l'apparition de la menace islamiste au Maroc. Même si cette menace qui s'est concrétisée par des actes de violence (assassinat de Omar Bengelloun en 1975) a été exploitée par le pouvoir et dirigée contre la gauche, le pouvoir institue, au lendemain de la révolution iranienne (1979), des Conseils Régionaux des ouléma en 1980, et un Conseil Supérieur des Ouléma présidé par le roi lui-même (1981). La politisation de l'islam par l'islamisme conduit le pouvoir à politiser les ouléma, ces gestionnaires de son islam. En effet, à travers les conseils institués, il est demandé ouvertement aux ouléma de se mêler de politique, autrement dit de lutter contre «les courants subversifs et déviationnistes ${ }^{67}$ » de l'islamisme. Selon A. Yassine, les ouléma ont répondu à cet appel: ils ont condamné la révolution iranienne parce que «le Roi a conseillé aux ouléma de dépasser le stade des vétilles (femmes nues, vin, cinéma...) et de se hausser vers des prises de position politiques ». Pour le pouvoir, l'implication des ouléma dans la politique implique leur engagement, en tant que fonctionnaires de l'État, dans la défense des intérêts politico-religieux du Makhzen. Les ouléma ne doivent pas adopter des positions populistes susceptibles de légitimer l'islamisme radical. La mise en garde du roi à l'adresse des ouléma va dans ce sens : « vous ne devez pas vous occuper de ce qui ne vous concerne pas, si par exemple le prix des cigarettes ou des carburants venait à être augmentée $^{8}$ ». Le roi demande donc aux ouléma, outre la condamnation de l'extrêmisme religieux, la légitimation de toutes les politiques sectorielles de l'État. Évidemment, pour les islamistes, ces ouléma sont, selon l'expression de A. Lamchichi, une «courroie de transmission de l'idéologie religieuse officielle et de légitimation des agissements du prince pervers, (ils) ne changent en rien la nature jahilite du régime ${ }^{69}$ ». 
801962 et 1974 sont donc deux dates historiques qui révèlent les soubassements des politiques religieuses de l'État. À chaque menace qui vise ce champ où il puise sa légitimité méta-constitutionnelle, le roi réagit par une politique appropriée, qui consiste à démontrer, par le biais des ouléma, que l'islamisme est une trahison de l'islam.

81 Mais tout en rejetant l'islamisme, le pouvoir tente de récupérer et de réinterpréter le "réveil islamique » à son profit. En effet, depuis la révolution iranienne, le pouvoir organise des colloques à caractère religieux : colloque de l'Imam Malik (avril 1980 à Fès), colloque du Cadi 'Ayyad (mars 1981 à Marrakech), colloque Bei'a et Califat en islam (septembre 1985 à Laâyoune). Dans la logique de cette tactique, le pouvoir fonde une université d'été consacrée au réveil islamique, dont la première session est tenue à Casablanca du 28 août au 3 septembre 1990. Le thème de sa première session est: «Le réveil islamique : réalités et perspectives ». La seconde session, tenue à Casablanca du 18 au 20 septembre 1991, s'intéresse au " rôle de l'orientation pédagogique islamique dans la construction de la société moderne ». Ces colloques sont financés par le roi. À l'occasion $\mathrm{du} \mathrm{XV}^{\mathrm{e}}$ siècle de l'hégire, ce dernier adresse une lettre ${ }^{70}$ au peuple marocain et à tous les membres de la communauté islamique. C'est la Lettre du Siècle dans laquelle il invite les musulmans à un retour aux sources et à l'établissement de l'État islamique. Dans cette lettre qui explicite la conception royale ${ }^{71}$ du réveil islamique, le roi exprime sa peur pour l'islam, désormais menacé par les musulmans eux-mêmes. Il définit l'islam comme une religion de symboles, et invite à ne pas s'arrêter au sens littéral de ses textes fondateurs. Il appelle également à un rapprochement entre sunnisme et shi'isme, et à un dialogue entre les ouléma des deux doctrines afin de créer le véritable réveil de l'islam.

82 Parallèlement à la récupération du réveil islamique, le pouvoir se livre à la répression des islamistes. Entre 1981 et 1984, il procède à l'arrestation de quelques groupes de la Chabiba appartenant spécialement au «Bataillon du Djihad» de A. Mouti'. Le procès du groupe des 71 (dont quelques membres sont arrêtés pendant l'été $1983^{72}$ ) a lieu en juillet 1984. Ses membres sont accusés de complot contre le roi et de volonté d'instauration d'une république islamique au Maroc. Treize condamnations à mort sont prononcées. Le procès du groupe des 26 (dont quelques membres sont arrêtés les 10-11 juillet 1985 ${ }^{73}$ ) voit Mouti' une deuxième fois condamné à mort par contumace. En 1984, c'est le groupe de Meknès (18 membres de la Chabiba) qui est arrêté.

83 La répression cible également Al-'Adl wa al-Ihsan. Au cours de l'été 1980, le pouvoir censure sa revue Al Jamâ'a et, en 1983, interdit son journal As-Sobh. A. Yassine est arrêté à cause de ses publications. En mai 1984, A. Yassine est condamné à 2 ans de prison ferme par le tribunal de Salé pour avoir proféré, dans As-Sobh, des «insultes gratuites» à rencontre des membres du gouvernement, de la radio et télévision marocaine. En juillet 1985 , le nº 16 de la Jamâ'a est censuré, puis la revue définitivement interdite. Plusieurs arrestations et procès ont lieu contre les prêcheurs de Al-'Adl wa al-Ihsan (procès de Kénitra, Agadir, Casablanca, Rabat, Taroudant, en février 1987). Mohamed Bachiri est interdit de prêches à la mosquée. Dès 1988, la police commence à encercler la maison de Yassine. Le 10 janvier 1990, les autorités décrètent la dissolution de la Jamâ'at Al-'Adl wa alIhsan. Quant à A. Yassine, il est mis sous résidence surveillée à Salé depuis décembre 1989.

L'islamisme est donc une réaction contre la suprématie de ce grand Autre, le Makhzen, à peine voilée par l'État de droit. En un sens, le caractère absolutiste du Makhzen a conduit au contre-absolutisme des islamismes marocains. La participation des partis politiques, depuis 1977, à une démocratie parlementaire formelle sans retombée socio-économique positive sur les couches sociales défavorisées et moyennes ne peut suffire à enrayer 
l'absolutisme et le contre-absolutisme. Au contraire, elle pousse le citoyen marocain à trouver dans l'islamisme une alternative proposant des lendemains qui chantent. La participation politique n'est plus crédible, elle est devenue un jeu au sens négatif du terme, quelque chose de " pas sérieux », incapable de produire cette illusion si nécessaire, fondamentale dans toute mobilisation. L'illusion est un aliment nécessaire à l'homme, et particulièrement aux masses néo-citadines, chassées de leurs campagnes, ruralisant les villes, mais ne trouvant pas dans celles-ci les fruits d'une industrialisation réussie... Selon Rémy Le veau "l'islam offre une réponse à ceux qui sont atteints par le chômage, à ceux qui ne croient plus à l'ascension sociale par le biais de l'effort et de la compétence, à ceux qui sont contestés dans leurs familles par leurs femmes ou filles, à ceux qui sont humiliés par le comportement choquant des étrangers et de la bourgeoisie marocaine occidentalisée ${ }^{74} »$.

Causalité sociale et causalité politique se complètent pour faire de l'islamisme une réaction contre la mise au pas des partis politiques par le pouvoir, désormais incapables d'exprimer les frustrations sociales. L'acceptation de la définition royale du concept d'opposition par la gauche signe l'échec idéologique et politique de la gauche, sa compromisssion avec le régime. Mais ce sont là les limites intrinsèques du modèle démocratique makhzénien qui a été mis en œuvre depuis le consensus néo-national de $L a$ Marche Verte. La menace militaire puis islamiste sont à l'origine de ce modèle qui débouche présentement sur l'intégration des acteurs politiques et para-politiques. Mais si le modèle semble contenir la menace militaire, ses insuffisances structurelles n'arrivent pas à extirper le charisme des modes islamistes de la contestation. En ce sens, l'islamisme reste une réaction ultime contre une démocratie de façade à laquelle il n'est pas convié. Al-islah wa at-tajdid est le seul mouvement islamiste marocain à avoir fait des concessions telles qu'il n'apparaît plus comme une inquiétante étrangeté. Ayant acepté la définition royale de l'opposition, fût-elle islamiste, le mouvement est autorisé à participer, non pas en tant que tel, mais indirectement sous l'égide du MPDC (comme on l'a vu plus haut). Après sa fusion avec la Rabita, association islamique, il a changé de nom et est devenu $\mathrm{Al}$ Islah wa at-tawhid. Moyennant quoi, à l'occasion des dernières élections législatives de décembre 1997, Al Islah wa at-tawhid, alias MPDC, obtient neuf sièges à la chambre des députés (lère chambre).

\section{Conclusion} islamiques institutionnels nous a permis en effet de dégager trois types d'islamisme: celui des ouléma indépendants, celui des associations éducatives qui contiennent en puissance une contestation politique, enfin celui des associations islamistes au sens strict qui utilisent la da'wa comme tremplin vers la contestation politique. L'islam est, dans le dernier cas surtout, à la fois un pré-texte et un texte dans la conquête du pouvoir politique.

Mis à part le cas des ouléma indépendants, à l'islamisme individuel limité, l'islamisme marocain, en tant que mouvement social organisé, n'est pas dirigé par des ouléma. Les trois leaders des associations islamistes marocaines ne sont pas des lauréats de la Qarawiyine ou de Dar El Hadith Al Hassaniya. Ce sont des personnages issus de 
l'enseignement moderne. Ce sont eux-mêmes des enseignants de langue arabe ou de disciplines scientifiques. Il semble ainsi que la formation des ouléma dans le système politique marocain et plus particulièrement leur fonctionnarisation, les orientent vers la légitimation. La contestation du régime par les ouléma est rare. Quand elle a lieu, elle démontre que la critique religieuse de l'État n'est pas nécesairement islamiste. L'islamisme n'est donc qu'une forme de la critique religieuse de l'État, la forme actuellement dominante.

2 - L'Autre et les autres de l'islamisme marocain. Les autres sont aussi diversifiés que l'islamisme lui-même. En outre, ils varient selon les situations et les intérêts. L'Autre, le Makhzen, est le même pour tous les islamismes : méfiant, répressif, peu tolérant dans le meilleur des cas, malgré les concessions majeures faites par Harakat Al-islah wa at-tawhid. Le changement d'attitude de cette association vis-à-vis du Makhzen a à peine ébranlé la position méfiante de ce dernier à l'égard de l'islamisme. Pour comprendre cette méfiance, on peut parler d'un islam monopoliste d'État : celui-ci ne reconnaît ni idéologiquement ni politiquement l'islamisme comme une autre vision de l'islam. L'État monopolise la légitimité religieuse en tant que légitimité politique, et érige son interprétation particulière de l'islam en islam véritable.

903 - L'évolution des islamismes marocains. À ce propos, notons les transformations suivantes: passage du mouvement (clandestin) à l'association (légaliste), passage de la révolution à la réforme. Le changement de nom est également symbolique. À part la Chabiba qui se faisait appeler jam'iya (association) au début des années 1970, les autres associations refusent actuellement d'utiliser le terme jam'iya et lui préfèrent celui de haraka (mouvement) ou de jamâ'a (groupe). Jam'iya est en effet un terme moderne pour dire association, actuellement en vogue dans une société marocaine qui s'organise en société civile. En gardant la notion de jamâ'a, Al-'Adl wa al-Ihsan affiche une volonté de distinction par rapport aux associations «laïques » de la société civile naissante, voire même par rapport à Al-islah wa at-tawhid qui adopte le terme harakat à connotation profane. Préférer le terme jamâ'a, c'est garder une symbolique islamique minimale au niveau du nom, classificatoire de l'identité.

914 - La sociologie islamiste et la sociologie des islamistes. La première est, comme on l'a vu, non différentielle, holiste, elle ne se fonde sur aucune donnée empirique. La seconde, celle d'une nomenclature typologique des islamismes et de ses autres, semble être la seule à être facilement concevable dans une société pré-séculière. La sociologie de la religion au Maroc est-elle donc actuellement condamnée à n'être qu'une sociologie des islamismes ? N'est-il pas temps de produire une sociologie des croyances, des attitudes et des pratiques religieuses, même si l'athéisme et l'irréligiosité sont encore difficilement dicibles en situation d'enquête? Il nous semble que l'autocensure du sociologue participant est souvent l'obstacle premier à surmonter. 


\section{NOTES}

1. Mohamed Tozy, Champ et contrechamp politico-religieux au Maroc, Thèse de Doctorat, Marseille, Université Aix-Marseille, 1984. p. 114.

2. Mohamed DARIF, L'Islam politique au Maroc. Approche documentaire, Casablanca, Publications de la Revue Marocaine de Sociologie Politique, 1992, 3 e édition, p. 6. (en arabe).

3. A. BENANI, «Légitimité du pouvoir au Maroc: consensus et contestation », Soua'l, Paris, $n^{\circ} 6$, avril 1987, pp. 115-119.

4. Abdelfettah LAMCHICHI, Islam et contestation au Maghreb, Paris, L'Harmattan, 1989, p. 179.

5. Abdessamad DIALMY, "L'intellectuel marocain : de la révolution à l'intégration », Libération, Casablanca, 11 octobre 1991.

6. Congrès International des Prêcheurs du Vendredi, Rabat, Publications du Ministère des Awqaf et des Affaires Islamiques, 1987 (en arabe).

7. Abdelaziz BENSEDDIQ, «La mission du savant ", Majma' al bahrayn, Tanger, première année, $\mathrm{n}^{\circ} 3$, septembre 1988, pp. 1-4.

8. Abdelaziz BENSEDDIQ, "Fetwa à propos de la crise du Golfe », Majma' al bahrayn, Tanger, troisième année, $\mathrm{n}^{\circ} 16$, pp. 2-6.

9. Les oulémas qui ont soutenu l'Irak ont été destitués par le ministère. Leur réaction a été critique à l'égard du ministère. Deux communiqués publiés respectivement dans Al Ittihad al Ichtiraki (Casablanca, 6 mars 1991) et Al Ousbou' Assiyassi (Casablanca, 22 mars 1991).

10. Communiqué de Al-'Adl wa al-Ihsan, Al Ittihad al Ichtiraki, Casablanca, 6 Mars 1991.

11. Publié dans Al Ittihad al Ichtiraki, Casablanca, 19 février 1991.

12. Publié dans Al Forqane, Casablanca, $n^{\circ} 23$, avril-mai 1991, p. 12.

13. Publié dans As Sahwa, Salé, $\mathrm{n}^{\circ} 3$, octobre 1991, p. 16.

14. Dans sa trajectoire intellectuelle, Taqi Eddine El Hilali abandonne la Tariqa Tijaniya pour devenir réformiste (salafi) sous l'impulsion de Mohamed ben Larbi El Alaoui. En 1946, il publie une revue sous le titre: Lissan Eddine (Le porte-parole de la religion). En 1974, il se consacre entièrement à la Da'wa et donne des cours dans quelques mosquées de Casablanca. Il est mort en 1987.

15. Abdeslam YASSINE, Al-ihsan wa ar-rijal. Salé, brochure intérieure, 1988.

16. Frère Musulman égyptien pendu par Nasser en 1965.

17. René LOURAU, Le gai savoir des sociologues. Paris, UGE / 10-18, 1977, p. 55.

18. Al Mithaq, Rabat, $\mathrm{n}^{\circ} 307,1975$.

19. Abdelkrim MoUTI', La révolution islamique : destin du Maroc actuel, sans éditeur, 1984, en arabe. Vingt ans auparavant, en 1965, Mehdi BEN BARKA avait publié L'option révolutionnaire au Maroc, dans lequel il appelait à une révolution de type marxiste. Ben Barka fut enlevé et assassiné à Paris.

20. Mounaddhamat al-Moujahidine bi al-Maghrib

21. Tandhime Jound Allah

22. Hizb At-tahrir al-Islami

23. Tandhim al Djihad al Mouqaddas

24. Harakat Ac-chabab al Islami At-tawri.

25. Abdelfettah LAMCHICHI, op. cit.. p. 183.

26. Communiqué de Abdelilah BenKIRANE, ex-président de la Jamâ'a Al Islamiya, Al Alam, Casablanca, 31 Juillet 1985. 
27. «Les islamistes au Maroc et la participation politique », Al Islah, Casablanca, 6 Janvier 1989, republié dans Ar Raya, Casablanca, 24 janvier 1992..

28. Abdelilah BENKIRANE, «Al Jamâ'at al Islamiya wa al-fiqh al haraki « (Les groupes islamistes et le droit (musulman) du mouvement (islamiste)). Al Isslah, Casablanca, n 15, 18 mars 1988, pp. 14-15. 29. Publié dans Arraya, Casablanca, 10 février 1992.

30. Interview exclusive de Abdelilah BENKIRANE, Le Quotidien du Maroc, Casablanca, 21-22 mai 1996.

31. Ibid.

32. La Koutla participationniste au processus démocratique se compose de quatre partis politiques: Istiqlal, USFP, PPS, et OADP. Les trois derniers partis représentent la gauche marocaine participationniste.

33. Lettre-Réponse de A. Khatib le 16 octobre 1972.

34. Plus tard, Abdelilah. Benkirane adoptera également une attitude favorable à l'égard de l'Iran : " avant de partir en Iran, j'avais à son encontre une image obscure (élaborée par le champ médiatique occidental et local, arabe, islamique et marocain)... mais dès que j'y suis allé, mes craintes et mes doutes se sont dissipés, et l'image m'est apparue tout à fait contraire ", Arraya, Casablanca, 2 avril 1996, p. 14.

35. Interview exclusive d'Abdelilah BENKIRANE, Le Quotidien du Maroc, Casablanca, 21-22 mai 1996.

36. lbid.

37. Françoise SOUDAN, «La longue marche d'Abdessalam Yassine », Jeune Afrique, $\mathrm{n}^{\circ} 1581$, avril 1991, pp. 17-23.

38. Abdeslam YASSINE, Lettre ouverte au roi Hassan II. L'Islam ou le déluge (1973). La lettre fait 144 pages. En voir l'analyse dans: "Epître-pamphlet de A. Yassine contre le Roi Hassan II", L'islamisme aujourd'hui. Sou'al, Paris, n 5, avril 1985, pp. 151-157.

39. Communiqué explicatif de Al-'Adl wa al-Ihsan, Majma' Al-bahrayn, Tanger, $\mathrm{n}^{\circ}$ 14, 1989.

40. Abdeslam YASSINE, Méditations sur le droit et l'histoire (Nadarat fi al Fiqh wa Attarikh), Mohammedia. Imprimerie Fédala, 1989, p. 82.

41. Abdeslam yASSINE, Al Jamâ'a, Salé, $n^{\circ}$ 5. p. 13. Ce numéro a été saisi.

42. Voir ce communiqué dans Arraya, Casablanca, n 4, 29 novembre 1990, pp. 8-9.

43. Interview de Abdelilah BENKIRANE, Le Quotidien du Maroc. 21 et 22 mai 1996. Cependant, même Al Mouharrir, l'ex-quotidien de l'USFP, sous le titre "Tourisme ou dépravation des mœurs", mettait en cause les clubs méditéranéens devenus des lieux de débauche.

44. Abdeslam YASSINE, Lettre ouverte au roi Hassan II. L'Islam ou le déluge, op. cit.

45. Abdeslam YASSINE, L'Islam demain : l'action islamique et le mouvement de la méthode prophétique à l'époque de la fitna, Casablanca, Imprimerie Ennajah, 1972, pp. 470 et suivantes (en arabe).

46. Ibid,. p. 3 et ss.

47. Abdeslam YASSine, Editorial, Al Jama'a. Salé, n 4, p. 13.

48. Abdeslam YASSINE, Lettre... citation extraite de A. BENANI, «Légitimité du pouvoir au Maroc: consensus et contestation », Soua'I, Paris, n 6, avril 1987, pp. 116-119.

49. Abdeslam YASSINE, L'Islam demain... op. cit., p. 470.

50. Mais dans un esprit d'objectivité, il faut reconnaître que même la sociologie marocaine dite académique ne peut répondre à de telles interrogations. Les sociologies empiriques de la religion et de la sexualité sont encore très en retard au Maroc.

51. Voir à ce propos notre texte "Féminisme et islamisme dans le monde arabe : essai de synthèse ", Social Compass, Londres, Vol 43, n 4, décembre 1996.

52. Libération, Casablanca, 26 septembre 1980.

53. Arraya, Casablanca, 2 avril, 1996, p. 4.

54. Interview de Abdelilah BENKIRANE, Le Quotidien du Maroc, Casablanca, 21 et 22 mai 1996.

55. Arraya, Casablanca, 16 avril 1996, p. 15. 
56. M. DUTEUIL, «L'intégrisme islamique au Maghreb : $3^{\mathrm{e}}$ partie, le Maroc », Grand Maghreb. Paris, n²9, 19 mars 1984, p. 41.

57. Arraya, «Le Soudan et le complot international, l'embargo attendu », Casablanca, 2 avril 1996, p. 9.

58. Arraya, Casablanca, 2 avril 1996, p. 4.

59. Ibid., p. 14.

60. Ibid., p. 8.

61. Al-'Adl wa al-ihsan, Communiqué explicatif, Majma' Al-Bahrayn, Tanger, $\mathrm{n}^{\circ} 14,1989$

62. Pierre LAMBERT. "Point de vue sur les jeunes étudiants marocains ", L'Afrique et l'Asie modernes. Paris, $\mathrm{n}^{\circ}$ 117, 1978.

63. Paul ChAMBERgEAT, «Le référendum constitutionnel du 7 décembre 1962 au Maroc », Annuaire de l'Afrique du Nord, Aix-en-Provence, 1962, pp. 182-183. Voir également, le quotidien At-tahrir, Casablanca, 25 et 27 novembre 1962.

64. Ce Ministère est responsable de l'application de la politique religieuse de l'État: il a pour mission de contrôler les écoles coraniques, de veiller sur la renaissance du patrimoine islamique, d'organiser les séances d'orientation religieuse, de désigner les prêcheurs du Vendredi et de destituer ceux qui dépassent les lignes tracées ou qui refusent de lire les prêches officiels.

65. La Ligue des Ouléma du Maroc a été créée par le pouvoir afin de minimiser le crédit religieux de l'Istiqlal.

66. Discours du Roi du 11 juin 1984.

67. Déclaration du Roi Hassan II dans Maroc Magazine, Casablanca, $n^{\circ} 218,3$ février 1980.

68. Discours du Roi lors de la première session du Conseil Supérieur des Ouléma, Le Matin du Sahara, Casablanca, 17 juillet 1982.

69. Abdelfettah LAMCHICHI, op. cit., p. 104.

70. Rédigé à Fès le $1^{\mathrm{er}}$ Moharram 1401 (Jour de l'an), correspondant au 9 novembre 1980.

71. Discours du Roi dans Le réveil islamique: réalités et perspectives. L'université d'été du réveil islamique, Ministère des Awqaf et des Affaires Islamiques, Rabat, 1990, Tome I, pp.14-18 (en arabe).

72. Al Alam, Casablanca, $1^{\mathrm{er}}$ août 1984.

73. Al Bayane, Casablanca, 24 août 1985 et 4 septembre 1985

74. Rémy LEVEAU, «Réaction de l'Islam officiel au renouveau islamique au Maroc », Annuaire de l'Afrique du Nord, Aix en Provence, CRESM, 1979.

\section{RÉSUMÉS}

Défini comme un déviationnisme par le pouvoir politique en raison de son opposition de nature religieuse, l'islamisme marocain est-il condamné à rester toujours l'Autre, cette inquiétante étrangeté ? Son éclatement entre radicalisme révolutionnaire et institutionnalisation réformiste n'est-il pas la prémisse de son intégration partielle au jeu politique?

L'accès au statut de parti lui étant interdit, le passage du statut de mouvement islamiste violent à celui d'association culturelle légaliste est la stratégie fondamentale, le mécanisme institutionnel qui rend possible l'intégration politique de l'islamisme. Mais cette transition n'englobe pas tous les islamismes du Maroc. L'association Al-'Adl wa al-Ihsan par exemple, tout en n'investissant pas la notion radicale de jahiliya dans sa sociologie politique spontanée, prône toujours l'instauration 
d'un État califat unifié.

Dirigé par des leaders issus de l'université moderne, l'islamisme marocain est resté jusqu'à présent une réaction populiste ultime contre une démocratie dite de façade à laquelle il commence cependant à être convié avec une grande prudence, et jamais en tant que tel.

Is Moroccan Islamism, being defined by the political power as a deviation from Islam given its religious opposition, condemned to always remain the Other, this disquieting strangness? Isn't its break-up in revolutionary radicalism and reformist institutionalization the begining of its partial integration in the political game?

Since it is forbiden to become a party, then the transition from the status of a violent islamist movement to that of a legalist cultural association is a fundamental strategy, the institutional mechanism which makes the political integration of islamism possible. However, this transition does not include all moroccan islamist movements. For example, Al-'Adl wa al-Ihsan association, without even investing the radical notion of jahiliya in its spontaneous political sociology, always advocates the insituting of a unified califal state.

Run by leaders coming from the modern university, moroccan islamism has so far an ultimate populist reaction to a democracy said to be a façade democracy, and to which it has begun nonetheless to be invited with great caution, but never as a movement.

Definido como un deviacionismo por el poder politico debido a su oposicion de naturaleza religiosa, el islamismo marroqui esta condenado a permanecer siempre al otro, es decir esta inquietante cosa extrana? Su estallido entre radicalismo revolutionario e institucionalisacion reformista no es la premisa de su integracion parcial en el juego politico?

Siendo prohibido para el todo acceso al estatuto de partido politico, le queda el paso de un movimiento islamista violento a el de una asociacion cultural legalista. Es la estrategia fundamental y el mecanismo institucional que le permite toda integracion politico. Pero este poso no concierne todos los islamistas de Marruecos. La asociacion Al-'Adl wa al-Ihsan, sin mayor utilizacion de la nocion radical de jahilya en su sociologia politico espontanea, sigue reivindicando la instauracion de un Estado califal unificado.

Dirigido por lideres formados en universidades modernas, el islamismo marroqui ha permanecido hosta hou una reaccion populista ultima contra une democracia calificado de aparente la cual sin embargo empieza a ser convidado, con gran prudencia, pero nunca como tal.

\section{AUTEUR}

\section{ABDESSAMAD DIALMY}

Université de Fès, (Maroc) 